\title{
Comparison of modern high-speed vitrectomy systems and the advantages of using dual-bladed probes
}

\author{
R. Oravecz, D. Uthoff* (D, N. Schrage and R. M. Dutescu
}

\begin{abstract}
Purpose: This study analyzes the efficiency of different vitrectomy systems and compares single with double-bladed cutters.

Methods: The systems EVA ${ }^{\mathrm{TM}}$ (DORC), Constellation ${ }^{\circledR}$ Vision System (ALCON), megaTRON S4 ${ }^{\text {HPS }}$ (Geuder) and Stellaris ${ }^{\circledR}$ PC (Bausch and Lomb) were used. We chose 20G and 23G probes, since not all systems had switched to a smaller $G$ at the time the study was conducted in 2016. Cut rates were varied in increments of 1000 cuts $/ \mathrm{min}$ from $500 \mathrm{cpm}$ to the system's maximum and vacuum pressures were varied in increments of $100 \mathrm{mmHg}$, from 100 to $600 \mathrm{mmHg}$ up to the individual system's maximum. In this study water, egg white, Pluronic ${ }^{\circledR}-\mathrm{F} 127 \mathrm{gel}$ and isolated porcine vitreous were used as models of human vitreous. The vitrectomy efficiency was calculated from the aspirated mass (g) within $30 \mathrm{~s}$. The aperture of the different vitrectomy probes was filmed with a high-speed camera.

Results: The area under the curve analysis showed differences in efficiency between vitrectomy systems. For water, a reverse relationship between the aspirated mass and cut rate was shown. By contrast, for most systems aspirated egg white and porcine vitreous showed a non-linear increase or decrease for $4000 \mathrm{cpm}$ and above. For all vitreous surrogates, EVA ${ }^{\mathrm{TM}}$ 's double-bladed probe aspirated significantly $(\mathrm{p}<0.001)$ more vitreous than its mono-bladed probe. Video recordings showed less vitreous traction for double- in contrast to single-bladed probes.

Conclusion: We can demonstrate differences in the efficiency of vitrectomy depending on the vitrectomy system used. Double-bladed probes were more efficient and probably safer than single-bladed probes.
\end{abstract}

Keywords: Vitreous, Vitrectomy, 20 gauge, 23 gauge, Vitreous model

\section{Key messages}

- Despite the size, there are differences in the efficiency of vitrectomy depending on the vitrectomy system used.

- Double-bladed probes were more efficient in working up vitreous compared to single-bladed probes.

- Except for EVA ${ }^{\mathrm{TM}}$, high cut rates adversely affect vitreous removal.

*Correspondence: uthoff@acto.de

Aachen Centre of Technology Transfer in Ophthalmology (ACTO E.V.),

An-Institute, RWTH-University, Karlsburgweg 9, 52070 Aachen, Germany

\section{Introduction}

The closed pars plana vitrectomy, established by Robert Machemer in 1971, has advanced to the most frequently applied therapy of vitreoretinal pathologies over recent decades [1]. These pathologies include vitreous hemorrhage, complicated retinal detachment, macular hole, intraocular foreign body or endophthalmitis [2-7]. Starting with 14- and 17-gauge single-port vitrectomy, O'Malley and Heintz then introduced the 20-gauge, three- port vitrectomy in 1975 [8]. Current microincision vitrectomy systems (MIVS) promote self-sealing sutureless sclerotomies, such as the 23-gauge sclerotomies 
developed by Eckardt, and the further minimization to 27 -gauge by Oshima et al. $[9,10]$.

Aside from the further miniaturization of the scleral incision to mitigate trauma of the surgical procedure, a primary goal of recent vitreoretinal research is to increase the efficiency of the vitrectomy. To attain higher efficiency, one should bear in mind that vitreous removal is influenced by the sclerotomy size, the duty cycle of the vitrector (cut rate and aspiration), the infusion pressure and the aspiration vacuum. Regarding miniaturization, special attention needs to be devoted to the problem of flow in small diameter tubes.

In recent years high-speed vitrectomy systems with a cut rate of up to 10,000 cuts/minute (cpm) have become especially popular, due to higher cut rates causing decreased retinal traction [11]. Moreover, increasing the infusion pressure from around $30 \mathrm{mmHg}$ in 20 -gauge vitrectomy systems to $50 \mathrm{mmHg}$ in 23- to 27 -gauge systems allows for a sufficient flow rate through an ever-smaller diameter. Nevertheless, even with a maximum aspiration pressure, the aspiration rate in 25-gauge vitrectomy is lower than that of a 20-gauge system [12]. With respect to the duty cycle and movement of cutter blades, parabolic (pneumatic) and trapezoid (double pneumatic) cutter movements both have a decreased duty cycle at $1500 \mathrm{cpm}$ compared to $600 \mathrm{cpm}$, although sinusoid (electric) duty cycles did not differ even at higher cut rates [13].

A novel development is the Ultravit High Speed Vitrectomy Probe (Constellation ${ }^{\circledR}$ Vision System, Alcon) which operates the vitrector blades by bidirectional pulsed air in contrast to the current spring release mechanism $[14,15]$. Furthermore, the Dutch Ophthalmic Research Center (DORC) (Zuidland, The Netherlands) introduced a vitrector with two angled blades, promising improved fluid dynamics and higher cut rates [16].

Regarding fluid control, the aspiration flow at the cutter orifice is difficult to control, as liquid removal depends not only on the vacuum pressure, but particularly on the viscosity of the fluids. This shift in viscosity between BSS and vitreous can cause unfavorable vitreoretinal tractions. This was particularly noticeable when using venturi pumps and peristaltic pumps, however, this risk has been reduced $[12,17]$.

This study analyzes the vitrectomy efficiency as a function of vacuum pressure and cut rates and the vitrectomy system as a whole, including the respective machine and cutter applied. In addition, high-speed videos of the vitrector during a duty cycle were recorded to differentiate the characteristics of each vitrectomy system. We chose $20 \mathrm{G}$ and $23 \mathrm{G}$ probes since not all vitrectomy systems offered smaller probes at the time the study was performed in 2016.

\section{Materials and methods}

\section{Vitreous surrogates}

Tap water, Pluronic ${ }^{\circledR}$-F127 gel (Pluronic ${ }^{\circledR}$-F127, SigmaAldrich, Germany), egg white and porcine vitreous were employed as substitutes of human vitreous. Pluronic ${ }^{\circledR}$-F127 is a block-co-polymer of ethylene dioxide and propylene dioxide, and its viscosity is adjustable by varying its concentration and temperature.

The egg white was used within its shelf life. Eggs were stored at $4{ }^{\circ} \mathrm{C}$, and the experiments were conducted at a room temperature of $21{ }^{\circ} \mathrm{C}$. Porcine eyes were obtained from a local slaughterhouse in order to use their vitreous within $12 \mathrm{~h}$ of slaughter.

\section{Viscosity}

Viscosity measurements were run as a pre-test by using rotation viscometry (Rotational Viscometer PCE-RVI 2, PCE Deutschland GmbH, Germany). The rotation viscometer measures the force needed to rotate a spindle submerged in the substance. Based on the electronically recorded twist moment measured in $\mathrm{mPa} s / \mathrm{cP}$, which depends on the geometry and rotational speed of the spindle, the viscosity can be measured in $\mathrm{mPa} \mathrm{s} /$ $\mathrm{cP}(1 \mathrm{mPa} \mathrm{s}=1 \mathrm{cP}$ [centi-Poise]). Water has a viscosity of $1 \mathrm{mPa} s$ at $20^{\circ} \mathrm{C}$. The spindle L2 (original from the company) was utilized for the tests. Moreover, for simulating human vitreous, an anti-lyotropic Pluronic gel (Pluronic ${ }^{\circledR-}$ F127, Sigma-Aldrich, Germany) was used in different concentrations. The states of aggregation are fluid $\left(-10-20{ }^{\circ} \mathrm{C}\right)$ or firm $\left(22-37{ }^{\circ} \mathrm{C}\right)$, depending on the temperature. Consequently, the respective viscosity of Pluronic ${ }^{\circledR-}$ F127 gel at different concentrations was investigated as a function of temperature. Our aim was to find the particular concentration at room temperature with stable viscosity. In addition, the viscosities of the prepared porcine vitreous and egg white were measured under the same measuring conditions.

\section{Vitrectomy systems}

For comparing the efficiency and characteristics of modern vitrectomy systems, the following systems were examined: Constellation ${ }^{\circledR}$ Vision System (Alcon, Forth Worth, USA), EVA ${ }^{\mathrm{TM}}$ (Dutch Ophthalmic Research Center, DORC), Zuidland, The Netherlands), megaTRON $\mathrm{S}^{\mathrm{HPS}}$ (Geuder, Heidelberg, Germany), and Stellaris ${ }^{\circledR}$ PC (Bausch\&Lomb, New Jersey, USA).

The Constellation ${ }^{\circledR}$ Vision System is a dual pneumatic drive technology vitrectomy machine with a Venturi vaccum pump. 20G and 23G Ultravit $^{\circledR}$ high-speed vitrectomy probes were applied. Of the three duty cycles to choose from in the Constellation ${ }^{\circledR}$ Vision System (Port Biased Open for core-vitrectomy, Port Biased Closed), we chose the Port Biased Open, given its presumed 
higher vitrectomy efficiency. Moreover, the megaTRON $\mathrm{S} 4{ }^{\mathrm{HPS}}$ and the Stellaris ${ }^{\circledR}$ PC systems work with a Venturi vacuum pump as well. In contrast, the EVA ${ }^{\mathrm{TM}}$ system employs a peristaltic two-cylinder pump mechanism. For each system, the original cutters provided by the manufacturer were used. Additionally, the newly developed twin duty cycle (TDC) cutters in the EVA ${ }^{\mathrm{TM}}$ system and Mach2 in megaTRON S4 ${ }^{\mathrm{HPS}}$ systems were tested, all of which operate with double-bladed cutters.

Depending on the vitrectomy system, the maxima of the aspiration vacuum pressure and cut rates per minute (cpm) differ, as is summarized in Table 1.

\section{Vitrectomy}

All vitrectomy systems were evaluated using 20-gauge as well as 23-gauge vitrectomes submerged in water, $17.5 \%$ Pluronic ${ }^{\circledR}-$ F127 gel, egg white and porcine vitreous without infusion pressure in an open beaker. Starting at $500 \mathrm{cpm}$, the cut rates were increased stepwise (increments of 1000 cuts/min) until the maximum of the applied vitrectomy system was reached (5000 cuts/ min for megaTRON S4 ${ }^{\mathrm{HPS}}$ and Constellation ${ }^{\circledR}$ Vision System; 8000 cuts/min for $\left.\mathrm{EVA}^{\mathrm{TM}}\right)$. Starting at $100 \mathrm{mmHg}$, the aspiration pressure was increased in $100 \mathrm{mmHg}$ steps until a maximum of $600 \mathrm{mmHg}$, except for in the cases of the EVA ${ }^{\mathrm{TM}}$ and Constellation ${ }^{\circledR}$ Vision System (650 $\mathrm{mmHg}$ ), was attained (see Table 1).

Vitreous surrogates were filed in borosilicate open beaker glasses centered on a microbalance (SBS-LW2000A, Steinbers System, Germany). Vitrectomes were submerged in the test material, and vitrectomy was performed for each setting in triplicates for $30 \mathrm{~s}$. The aspirated test material was measured in grams as weight loss by means of elimination of vitreous through the vitrectomy system.

\section{High-speed video recordings}

To analyze the characteristics of the vitrectomes and their duty cycles, high-speed videos were recorded (CR3000 $\times 2$ high-speed video-camera, Optronis, Germany). Therefore, anterior segments of porcine eyes were removed, and vitrectomies were filmed under illumination (Multied LT-V8-15, Optronics, Germany). For each vitrector, videos were recorded with a stepwise increase in vacuum pressures and cut rates according to the aforementioned protocol.

\section{Statistical analysis}

To compare the mass aspiration of different vitrectomy systems and cutter designs for each vitreous surrogate, a two-tailed t-test was performed. For mono-bladed probes, the area under the curve analysis displays the aspirated mass against cut-rates from $0-6000 \mathrm{cpm}$ at a fixed $600 \mathrm{mmHg}$ aspiration pressure.

\section{Results}

\section{Viscosity of vitreous surrogates}

Water has a known viscosity of $1 \mathrm{mPa}$, which has been confirmed in our tests. Pluronic ${ }^{\circledR-}$ F127 in concentrations of $15 \%, 17 \%$ and $18 \%$ revealed similar viscosities in a narrow range of $18-25{ }^{\circ} \mathrm{C}$ (Fig. 1). Pluronic ${ }^{\circledR} \mathrm{F} 127$ in a concentration of $17.5 \%$ and with an estimated viscosity of around $40 \mathrm{mPa}$ s was used in our experiments. Higher viscosities like in porcine and human vitreous were not achieved, since a viscosity of even 18\% Pluconic F127 did not show a plateau in viscosity at a certain temperature. On the other hand, concentrations above $18 \%$ were too viscous to be worked off by vitrectors.

The native porcine vitreous showed high variation in viscosity between $60-200 \mathrm{mPa}$ s, which can be explained by its inhomogeneity based on its collagen and hyaluronic acid fundamental structure. The measurements of egg white also showed variable viscosity ranging from $45 \mathrm{mPa}$ s to $80 \mathrm{mPa}$.

\section{0-gauge and 23-gauge Vitrectomy \\ Water}

For the vitrectomy of water most systems showed a significant decline in aspirated mass at high cut rates (Fig. 2) This is the case for most systems except for 20G/23G megaTRON S4 ${ }^{\mathrm{HPS}}$ probes, $23 \mathrm{G}$ Constellation ${ }^{\circledR}$ probes and both double-bladed probes of $\mathrm{EVA}^{\mathrm{TM}}$ and megaTRON $\mathrm{S} 4{ }^{\mathrm{HPS}}$. Here, no significant differences $(\mathrm{p}>0.05)$ were seen for high cut rates compared to $0 \mathrm{cpm}$. For $\mathrm{EVA}^{\mathrm{TM}}$,

Table 1 Range of cut rates and aspiration pressures for the vitrectomy systems, S4 (Geuder, Germany), Stellaris ${ }^{\circledR}$ PC (Bausch \& Lomb), Constellation ${ }^{\circledR}$ Vision System (Alcon), EVA ${ }^{\mathrm{TM}}$ (DORC, The Netherlands)

\begin{tabular}{lllll}
\hline & $\begin{array}{l}\text { Stellaris PC Bausch \& } \\
\text { Lomb }\end{array}$ & $\begin{array}{l}\text { Constellation vision system } \\
\text { ALCON }\end{array}$ & Megatron S4 Geuder & Eva D.O.R.C. \\
\hline $\begin{array}{l}\text { Maximum Cut rate (cuts/ } \\
\text { min) }\end{array}$ & 5000 & $5000(20 \mathrm{G}), 7500(23 \mathrm{G})$ & $2500(20 \mathrm{G}), 6000(23 \mathrm{G})$ & 8000 \\
$\begin{array}{l}\text { Maximum Aspiration Pres- } \\
\text { sure (mmHg) }\end{array}$ & 600 & 650 & 600 & 680 \\
\hline
\end{tabular}




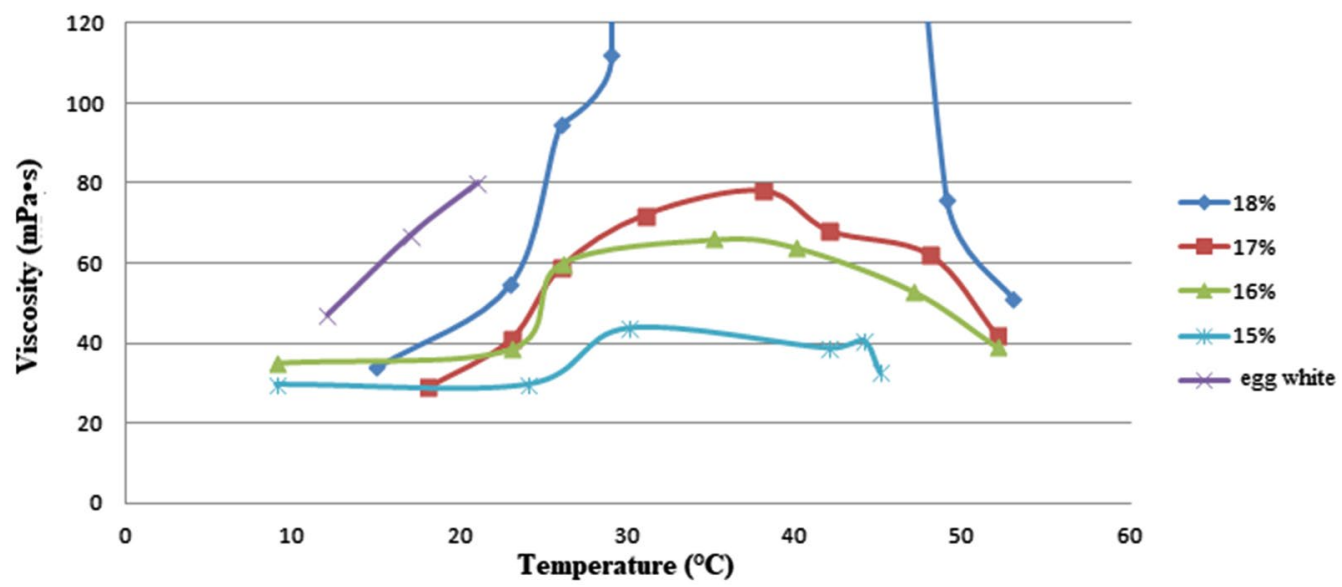

Fig. 1 Viscosity (mPa s) of egg white and Pluronic $\mathrm{F} 127^{\circledR}$ in concentrations of $15 \%$ to $18 \%$ as a function of temperature $\left({ }^{\circ} \mathrm{C}\right.$ )

the aspirated mass of water was significantly lower at $6000 \mathrm{cpm}$ compared to $0 \mathrm{cpm}$ for both $20 \mathrm{G}(\mathrm{p}<0.0001)$ and 23G $(\mathrm{p}<0.0001)$. Comparable results are shown for Stellaris ${ }^{\circledR}$ PC $(20 G, p<0.001,23 G, p<0.05)$ for cut rates at and above $3000 \mathrm{cpm}$ compared to $0 \mathrm{cpm}$. For Constellation ${ }^{\circledR} 20 \mathrm{G}$ probes significantly less $(\mathrm{p}<0.0001)$ mass was aspirated at $5000 \mathrm{cpm}$ compared to $0 \mathrm{cpm}$.

Comparing mono to dual-bladed probes, dual-bladed probes (Fig. 3) of megaTRON S4 ${ }^{\mathrm{HPS}}$ and $\mathrm{EVA}^{\mathrm{TM}}$ showed significantly higher $(\mathrm{p}<0.0001)$ mass aspiration of water compared to its mono-beveled vitrectors (Fig. 2). The mean percentual difference at different cut rates was $45 \%$ for megaTRON S4 ${ }^{\mathrm{HPS}}$ and $79.7 \%$ for $\mathrm{EVA}^{\mathrm{TM}}$.

\section{Pluronic gel}

Like water, the same relationship between cut rate vacuum and aspirated mass was detected when using Pluronic gel (Fig. 4). By considering its higher viscosity, less Pluronic gel was aspirated than water. Given the similarities between water and Pluronic gel regarding their homogeneity, further experiments were not performed on Pluronic gel.

\section{Egg white}

For egg-white high standard deviations did not allow for the defining of significant differences between different vitrectomy systems using mono-bladed probes (Fig. 5). In addition, no significant differences for the aspirated mass at low vs high cut-rates were detected. Nevertheless, the area under the curve analysis (Fig. 7) indicates some decline or a slower increase of aspirated mass with increasing cut rates for some systems.

The megaTRON S4 ${ }^{\mathrm{HPS}}$ and $\mathrm{EVA}^{\mathrm{TM}}$ dual-bladed probes did not significantly increase nor decrease the weight of the aspirated mass compared to mono-bladed probes.
This is based on a high standard deviation for some measurements (Fig. 3).

\section{Porcine vitreous}

Similarly to egg-white, the vitrectomy of porcine vitreous showed high standard deviations and therefore did not evidence significant differences between different vitrectomy systems using mono-bladed probes (Fig. 6). In addition, no significant differences for the aspirated mass at low vs high cut-rates were detected. Nevertheless, the area under the curve analysis (Fig. 7) indicates some decline or a slower increase of aspirated mass with increasing cut rates for some systems.

The megaTRON S4 ${ }^{\mathrm{HPS}}$ dual-cut vitrectors did not significantly alter the weight of the aspirated mass compared to its mono-bladed vitrector. Like with egg white, the dual cutter aspirated about the same amount of mass than the mono-bladed cutters at increasing cpm. For $\mathrm{EVA}^{\mathrm{TM}}$, at least at $6000 \mathrm{cpm}$, significantly more vitreous $(\mathrm{p}<0.01)$ was aspirated using its dual-bladed compared to its mono-bladed probe. The mean (vacuum 100$680 \mathrm{mmHg}$ ) percentual difference at $6000 \mathrm{cpm}$ was $117 \%$.

\section{Area under the curve analysis}

For a better comparison of the different systems, the area under the curve was analyzed with a fixed $600 \mathrm{mmHg}$ vacuum pressure for all vitrectomy systems, while increasing cut rates from 0-6000 cpm (Fig. 7). In summary, the $\mathrm{EVA}^{\mathrm{TM}}$ system aspirated more of the different vitreous surrogates than the other systems.

\section{High speed video recordings}

Blade movement during a duty cycle differs between various probes. Dual-bladed probes of the $\mathrm{EVA}^{\mathrm{TM}}$ and megaTRON S4 ${ }^{\mathrm{HPS}}$ systems showed constant vitreous 

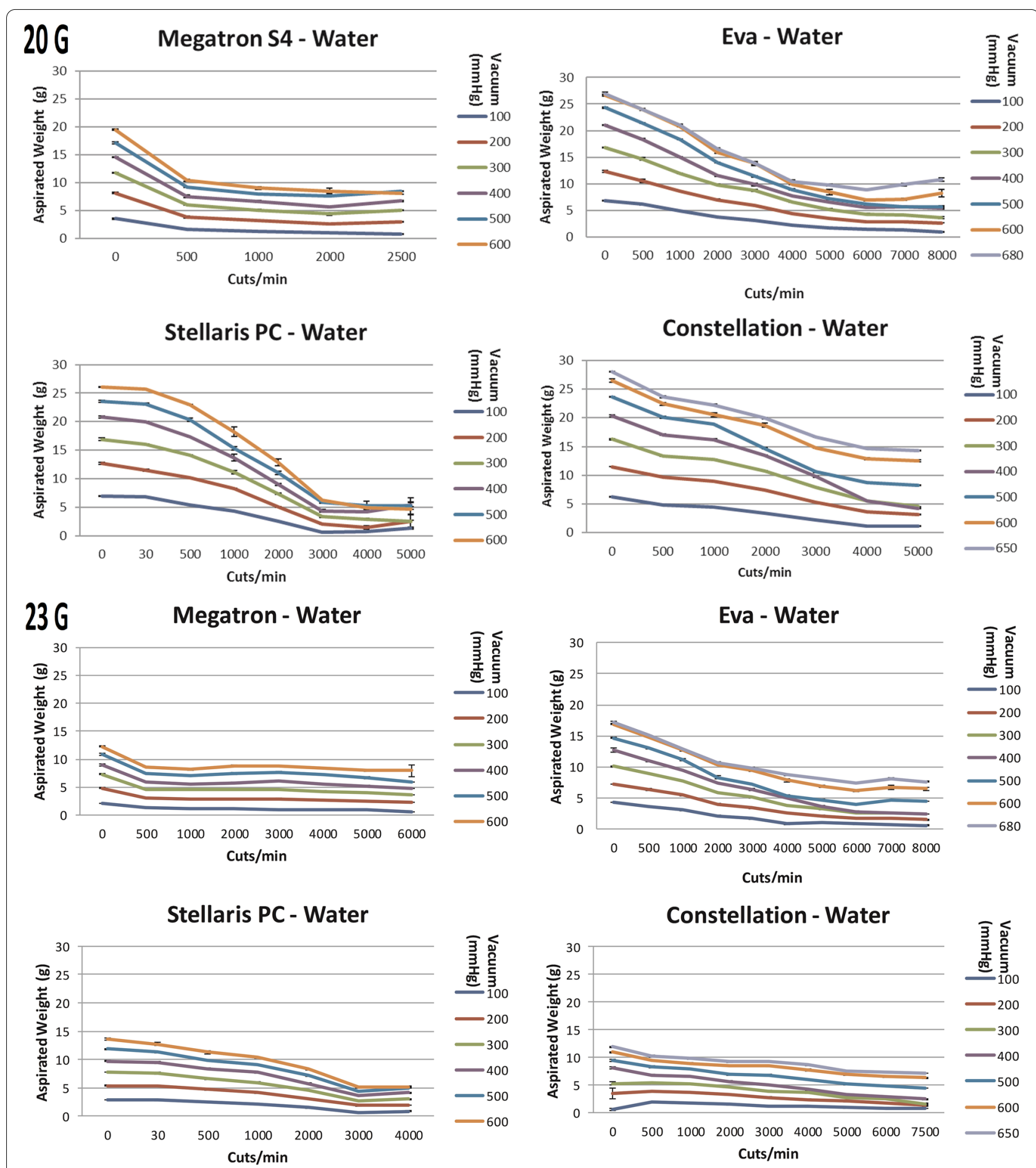

Fig. 2 The aspiration of water ( $\mathrm{g}$ ) as a function of cut rate and vacuum pressure for 20- and 23-gauge vitrectomes for the vitrectomy systems Constellation ${ }^{\circledR}$ Vision System, EVA ${ }^{\mathrm{TM}}$, megaTRON S4 ${ }^{\mathrm{HPS}}$ and Stellaris ${ }^{\circledR} \mathrm{PC}$

aspiration compared to an oscillatory and enhanced vitreous movement of the mono-bladed probes of the Constellation ${ }^{\circledR}$ Vision System, megaTRON S4 ${ }^{\mathrm{HPS}}$ and Stellaris ${ }^{\circledR}$ PC systems. As examples, videos of the duty cycle of the dual cut Mach 2 (megaTRON $\mathrm{S}^{\mathrm{HPS}}{ }^{\mathrm{H}}$ ) compared to the UltraVit dual pneumatic cutter (Constellation ${ }^{\circledR}$ Vision System) are shown (see Additional files 1, 2). 

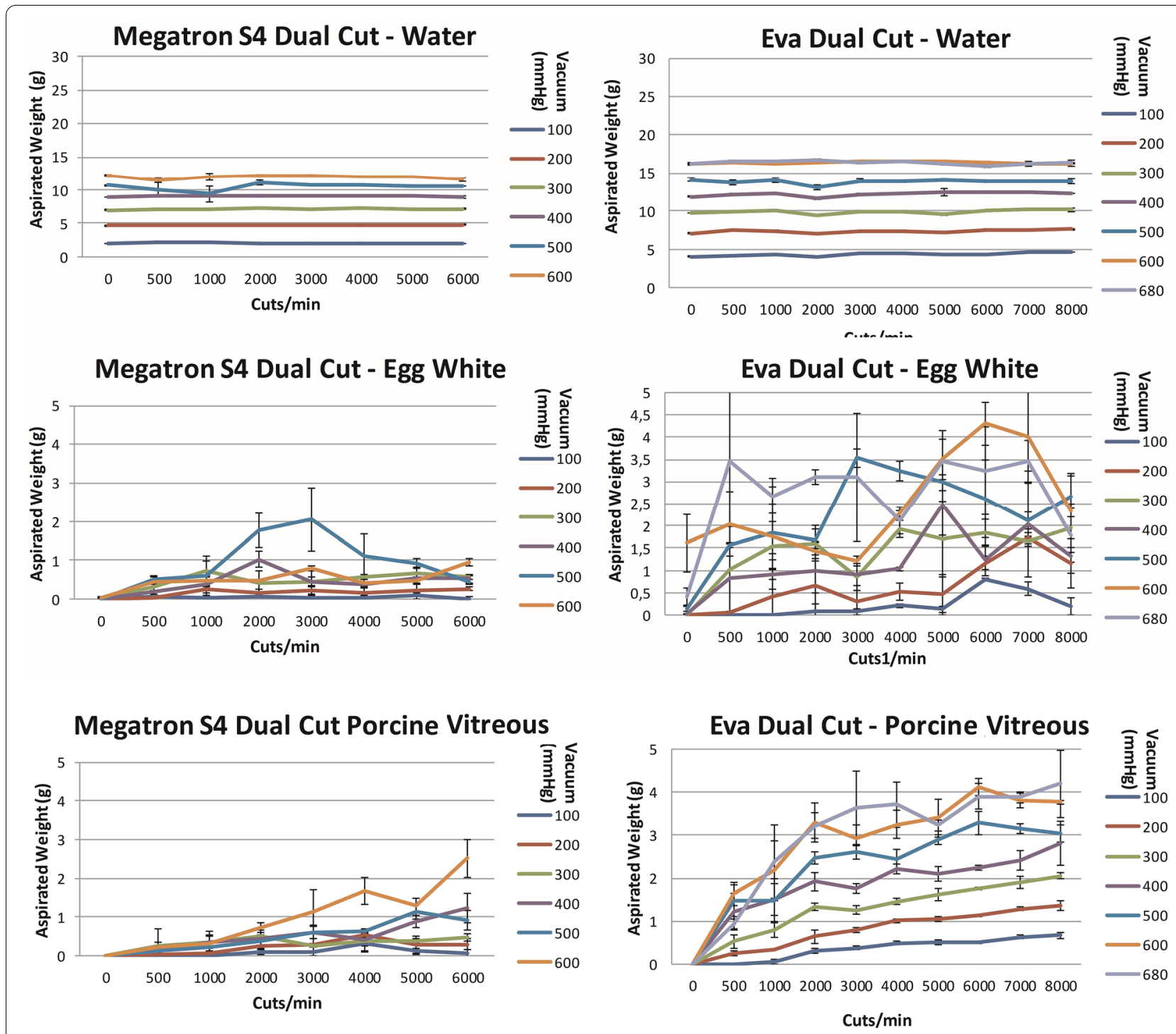

Fig. 3 The aspiration of water (g), egg white and porcine vitreous as a function of cut rate and vacuum pressure for 23-gauge dual-cut vitrectors for the megaTRON S4 ${ }^{\text {HPS }}$ and EVA ${ }^{\mathrm{TM}}$ vitrectomy systems

\section{Discussion}

In this study we can demonstrate different models of vitreous and their characteristics during vitrectomy using current vitrectomy systems. It could be shown that water and biological gels substantially differ from one another. For water, we found with increasing cut-rates a significantly lower volume passing through the vitrector for most systems. Given the homogeneity in viscosity of this Newtonian fluid, a cutting process is not necessary. Therefore, higher cut rates adversely affect the vitreous removal, since the total time of a closed cutter during the duty cycle increases with higher cut rates. This effect has been confirmed by Diniz et al. using the Constellation ${ }^{\circledR}$ system [17]. In their comparative study, cutter movements varied among the vitrectomes. The UltraVit dual pneumatic cutter of the Constellation ${ }^{\circledR}$ system transported more fluid than classical spring return vitrectomes, considering its fast blade movement as confirmed by our high-speed video recordings of the vitrectome port opening. However, we could not confirm significant differences between different monobladed cutters. Therefore, we made an area under the curve analysis, which revealed the advantage of the UltraVit/ Constellation ${ }^{\circledR}$ system, which was even more pronounced for $\mathrm{EVA}^{\mathrm{TM}}$ systems for all vitreous surrogates. One could speculate that the higher aspiration volume of the $\mathrm{EVA}^{\mathrm{TM}}$ system compared to their competitors is based on their novel pump system, which is neither a peristaltic 


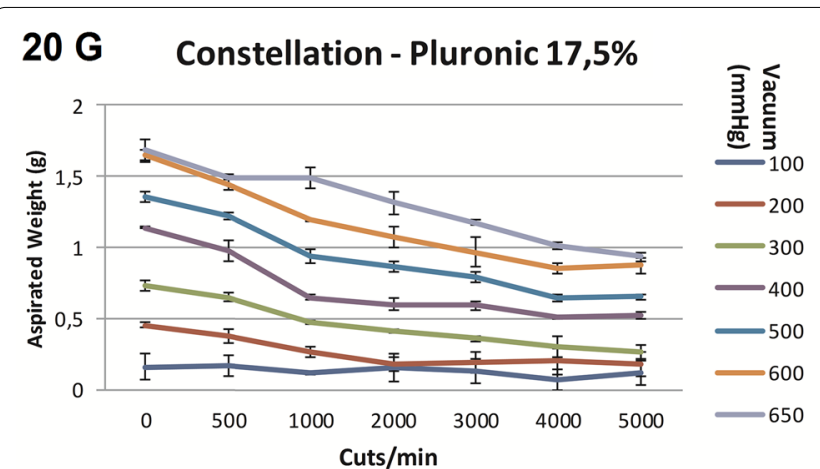

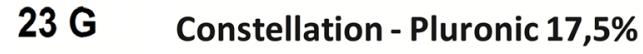
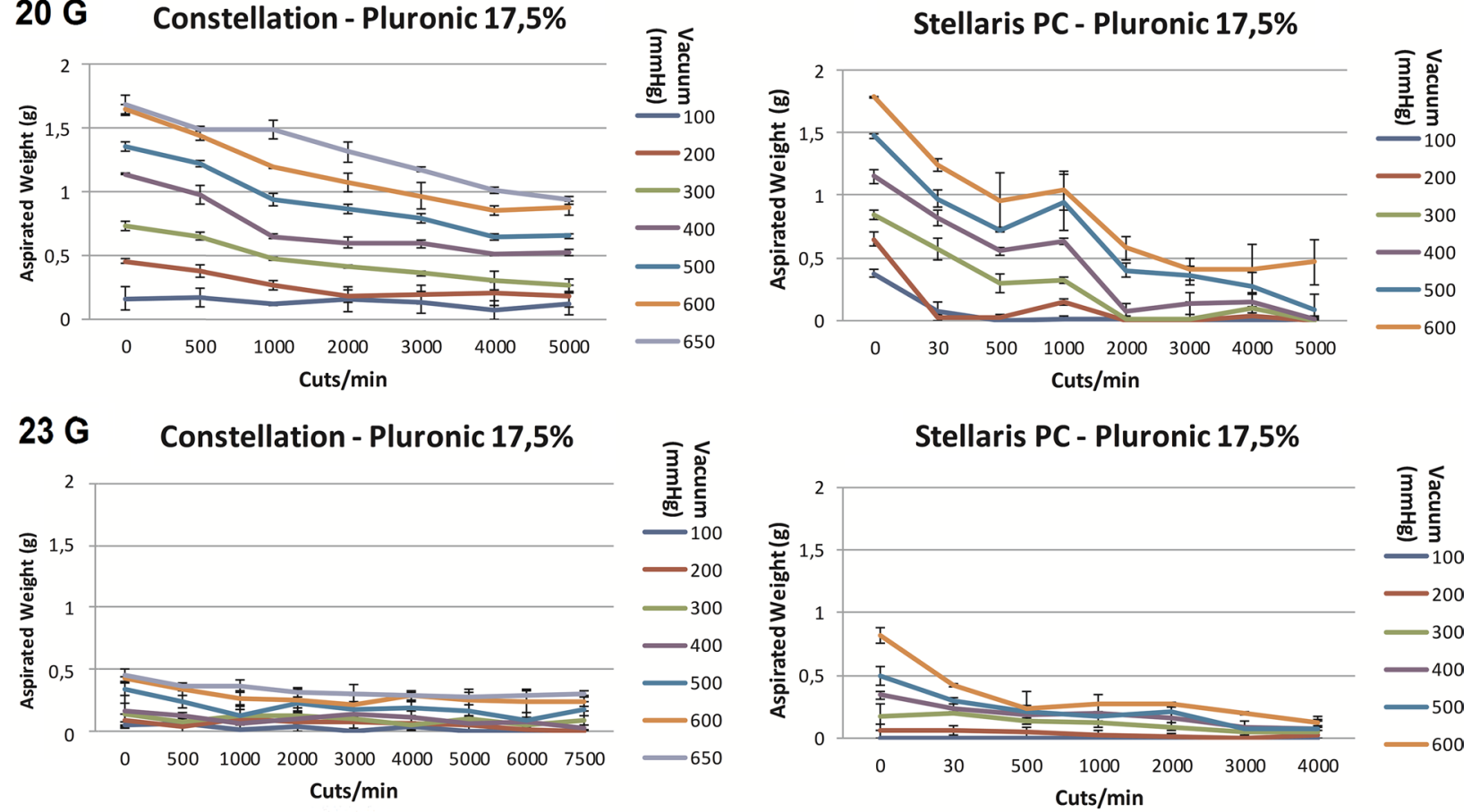

Fig. 4 The aspiration of Pluronic gel $(\mathrm{g})$ as a function of cut rate and vacuum pressure for 20- and 23-gauge vitrectomes for the Stellaris ${ }^{\circledR} \mathrm{PC}$, Constellation ${ }^{\circledR}$ Vision System, vitrectomy systems

nor a venturi pump. Their Vacuflow Valve Timing Intelligence (VTi) technology uses high-sensitivity pressure sensors and computer-controlled operating pistons, which generate a fast vacuum response and reduce undesirable flow turbulences [18]. In addition, its dual bladed probe showed significantly more water aspiration than its mono-bladed probe, supposedly due to the dual-bladedcutter port being open for $92 \%$ of the duty cycle, according to information from DORC.

Egg white and porcine vitreous are semi-solid substances consisting of over $90 \%$ water and additional proteins. Both substances may obstruct the cutter opening [19]. While egg-white contains proteins such as albumins, mucoproteins and globulins, porcine vitreous proteins are mostly made up of hyaluronan-derived uronic acid and collagen [20], comparable to the collagen fibers and hyaluronic acid of human vitreous. Consequently, porcine vitreous shows a comparable viscosity and viscoelastic behavior to human vitreous [21, 22]. The inhomogeneity of these two vitreous surrogates might explain the high standard deviation seen in our experiments that did not allow us to perceive significant differences between various vitrectors and systems. Therefore, we used an area under the curve analysis, which indicated an increasing porcine vitreous/egg white removal in each machine, except for Stellaris PC, with increasing cut rates. As expected, 23-gauge vitrectors removed about half the amount of vitreous compared to 20-gauge ports. One reason for these lower flow rates is certainly based on Hagen-Poiseuille Law, which describes the pressure drop in an incompressible Newtonian fluid exhibiting laminar flow through a long cylindrical pipe of constant cross section. One could expect even lower amounts of vitreous being removed using 25 or $27 \mathrm{G}$ devices. We excluded such devices from our study since not all producers had switched to a $25 / 27$ gauge in 2016 when this study was performed. 


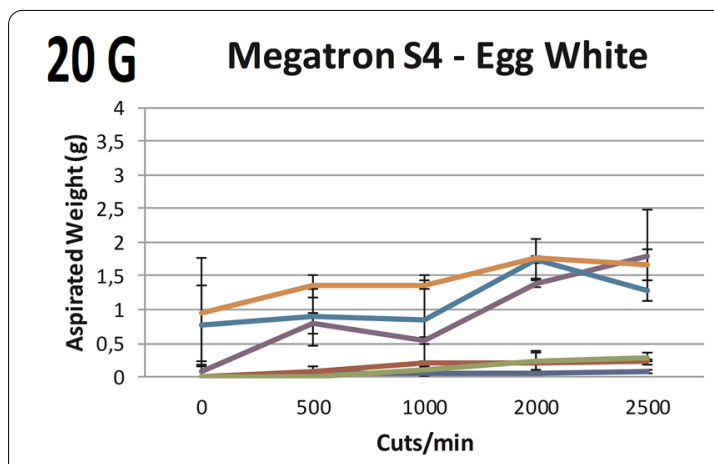

Stellaris PC - Egg White

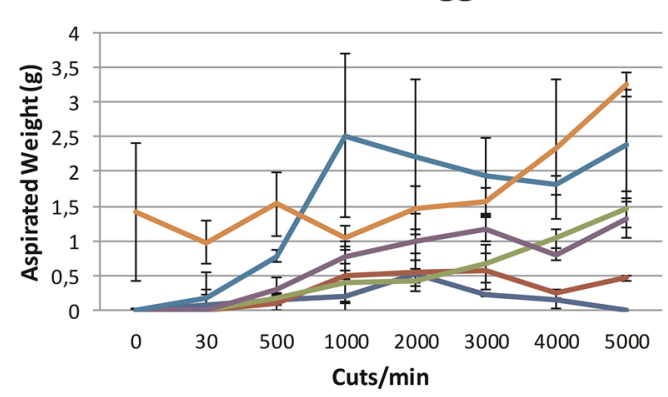

\section{$23 \mathrm{G}$ Megatron S4 - Egg White}

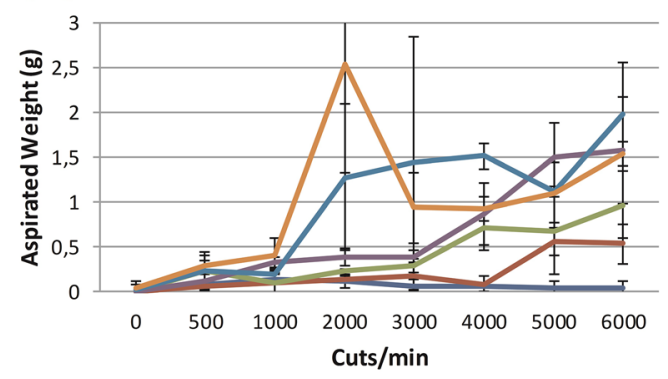

Stellaris PC - Egg White

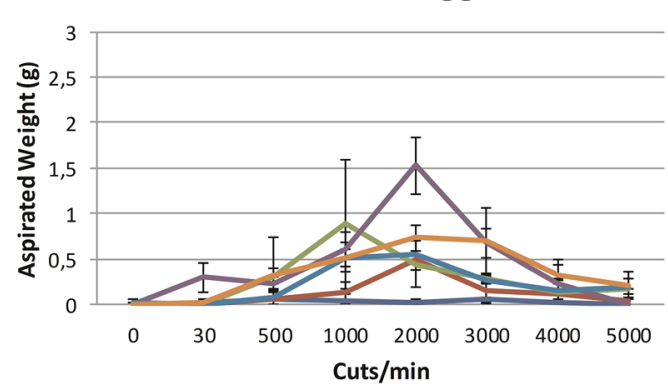

Eva - Egg White
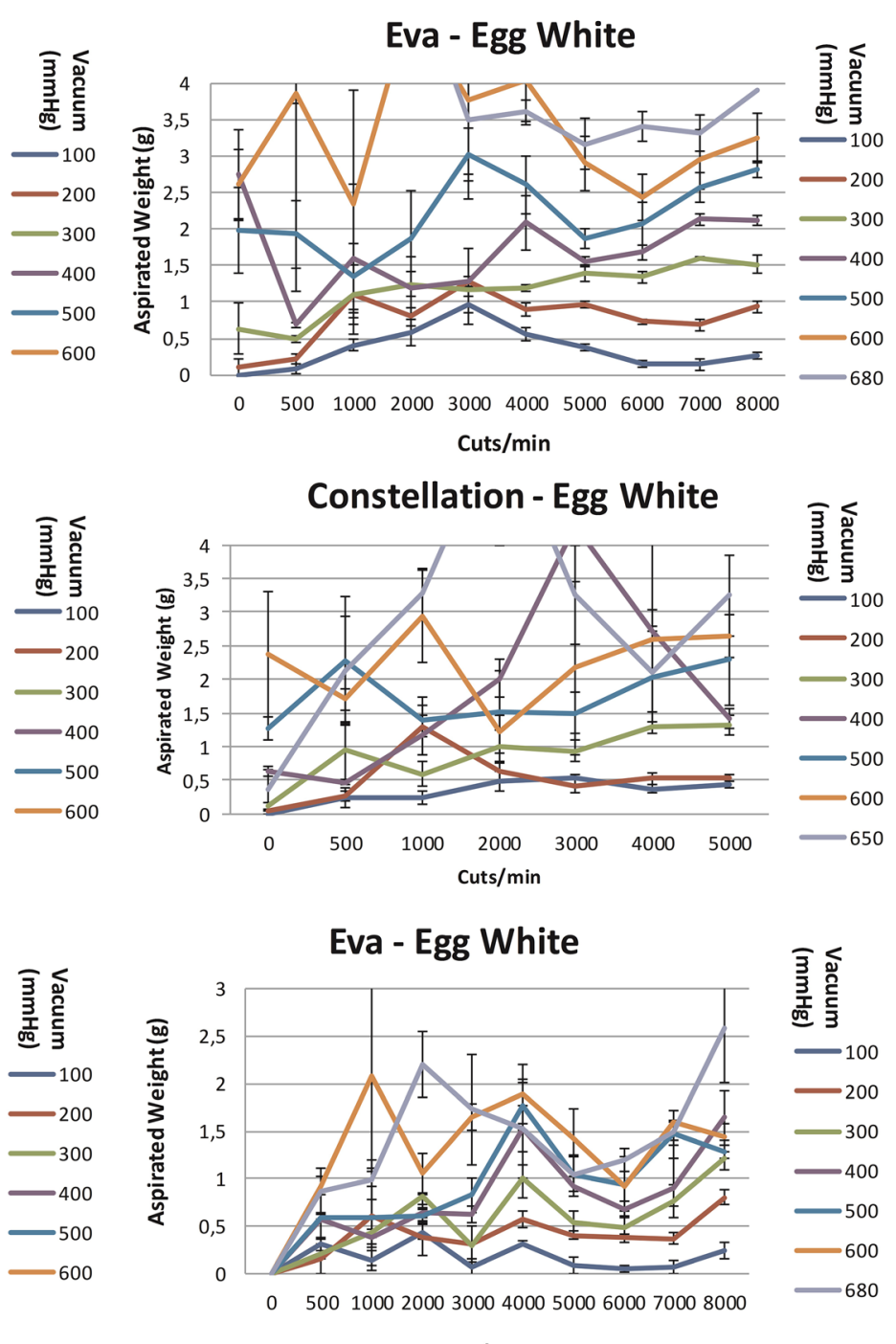

Eva - Egg White

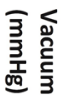

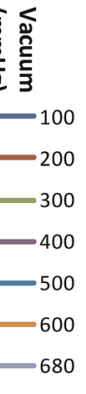

Cuts/min
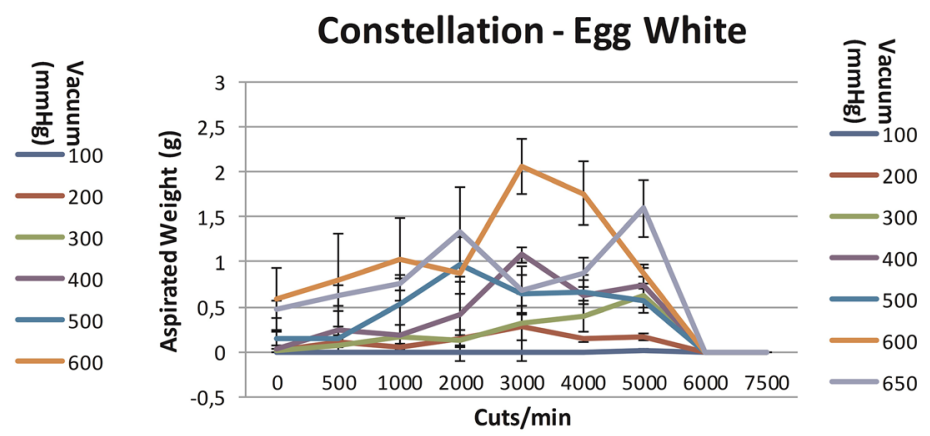

Fig. 5 The aspiration of egg white $(\mathrm{g})$ as a function of cut rate and vacuum pressure for 20- and 23-gauge vitrectomes for the vitrectomy systems Stellaris ${ }^{\circledR}$ PC, Constellation ${ }^{\circledR}$ Vision System, megaTRON S4 ${ }^{\mathrm{HPS}}$ and EVA ${ }^{\mathrm{TM}}$ 

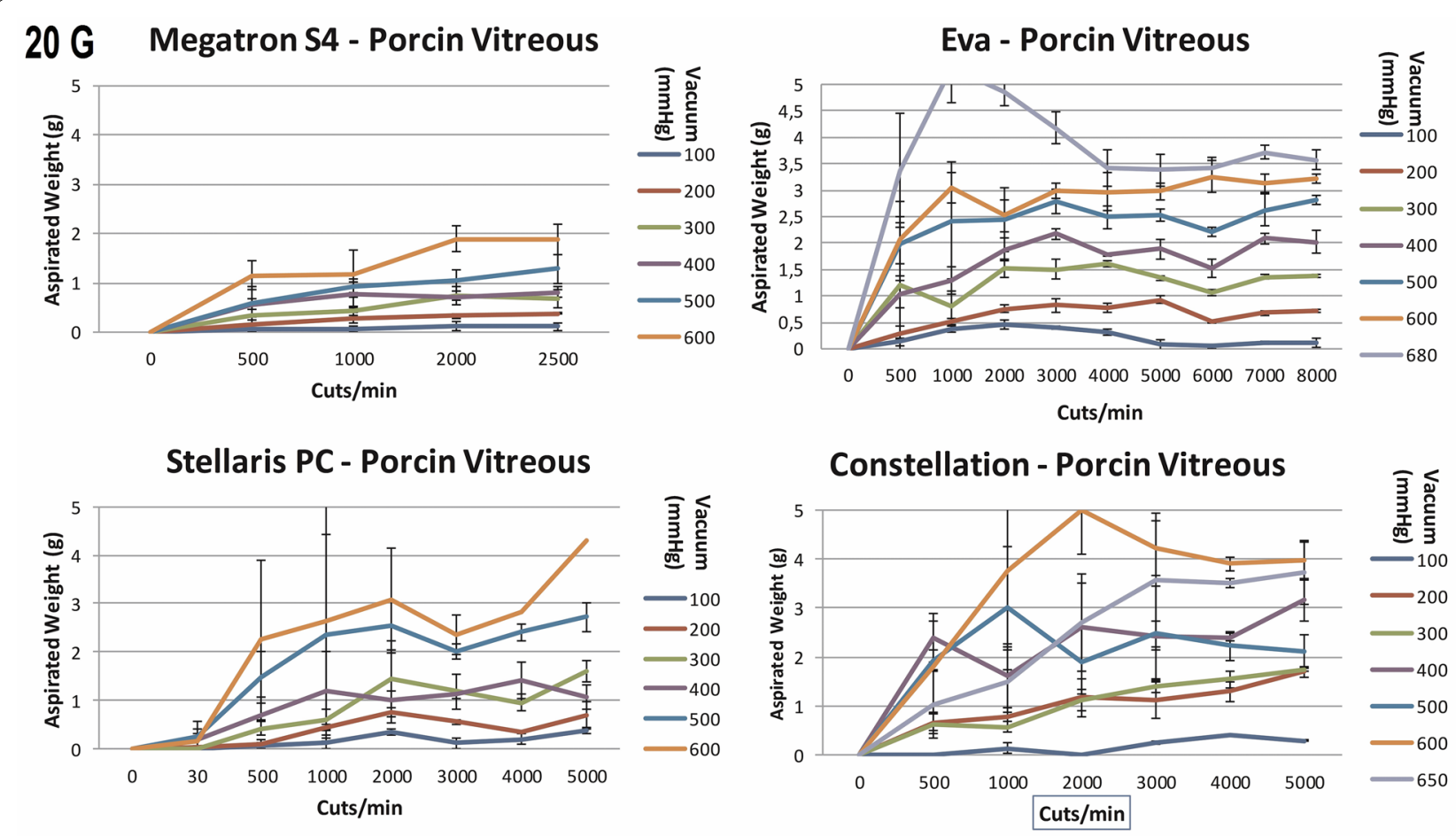

\section{G Megatron S4 - Porcin Vitreous}
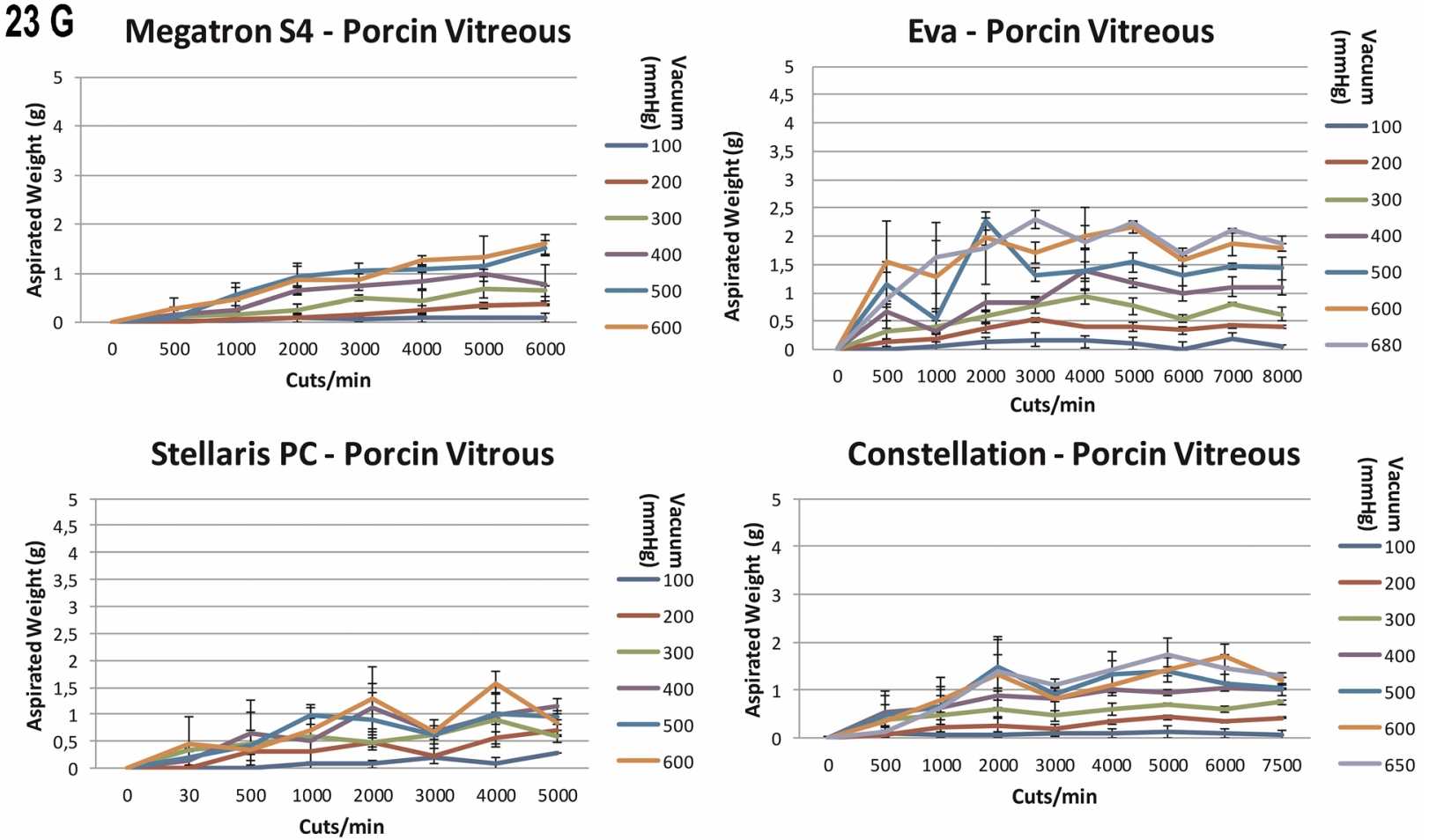

Fig. 6 The aspiration of porcine vitreous (g) as a function of cut rate and vacuum pressure for 20- and 23-gauge vitrectomes for the vitrectomy systems Stellaris ${ }^{\circledR}$ PC, Constellation ${ }^{\circledR}$ Vision System, megaTRON S4 ${ }^{\text {HPS }}$ and EVA ${ }^{\mathrm{TM}}$ 
(See figure on next page.)

Fig. 7 Area under the curve analysis of the aspiration of water (g), egg white and porcine vitreous as a function of cut rate and vacuum pressure for 20- and 23-gauge vitrectors for the vitrectomy systems Stellaris ${ }^{\circledR}$ PC, Constellation ${ }^{\circledR}$ Vision System, megaTRON S4 ${ }^{\mathrm{HPS}}$ and EVA ${ }^{\mathrm{TM}}$

The Dual-Cut cutters from Geuder and DORC showed some differences in performance. There was constant aspiration even at higher cut rates which, again, became significant only for $\mathrm{EVA}^{\mathrm{TM}}$ at $6000 \mathrm{cpm}$, presumably based on high standard deviations for the other experiments. Here, double-bladed vitrectors allow preforming forward and backward cutting of vitreous during blade movement, without complete closure of the cutter opening, which stands in contrast to standard guillotine-like cutters that have an increasing closure time at higher cut rates. This allows for a doubling of cut rates and might therefore increase the efficiency of vitrectomy even at higher cut rates. These results were confirmed by Pavlidis in a study of 80 patients using more novel two-dimensional (TDC) 25- and 27-gauge cutters (TDC, DORC International) for core vitrectomy. By using 25/27-gauge TDC rather than conventional cutters the overall core vitrectomy time could be reduced by $34-50 \%$ [23]. Another assumed disadvantage of mono-bladed probes is the safety issue, since complete port closure results in flow instability and fluid acceleration, which might cause retinal traction. This is consistent with our video imaging (Additional files 1,2) where we did not find the typical oscillations of the vitreous, due to vitrector-port opening and closing of mono-bladed probes in comparison to dual-bladed probes. However, we could not demonstrate differences between vitreo-retinal interactions depending on the vitrectomy system used. Lima et al. describe another cutter design, a dual port cutter. Like dual-bladed cutters, dual-port cutters have the advantage of a faster vitreous aspiration than monobladed cutters [24]. Using dual-port cutters does not eliminate the safety concern, as their blades completely occlude the port during blade movement. However, retinal traction could very well be overcome by using dual-port cutters with smaller lumina in 25/27-G cutters, as discussed in a more recent review [25].

Overall, there are similarities in Newtonian fluid transport between single-cut cutters that can be ascribed to higher flow at higher vacuum pressures. There are lower flow rates for smaller cutters. The flow rates decrease more or less with increasing cut rates, depending on the cutter system (spring- pneumatic duty cycle). For vitreous surrogates such as egg white and porcine vitreous, we found an increase in aspirated mass, depending on the vacuum pressure and cutting movement. Different maxima were achieved with different machines. In most cases the vacuum pressure and cut rate correlate with the aspirated mass.

For surgeons, it is crucial to gain information about the oscillation of the retina in critical situations and the reproducibility of suction and cut rates to manipulate the vitreous without harming the retina. Dual-cutters change the apparition of the cutting systems by causing less vitreous movement. Further studies should address whether less vitreous movement as described here ultimately causes less retinal traction and thus helps to avert retinal tear formation. 


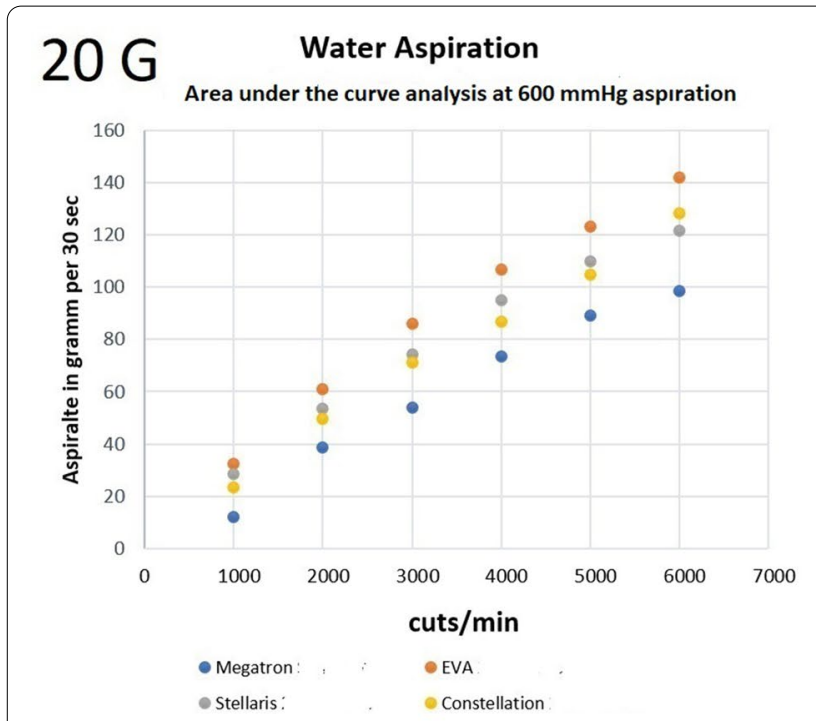

Egg White Aspiration

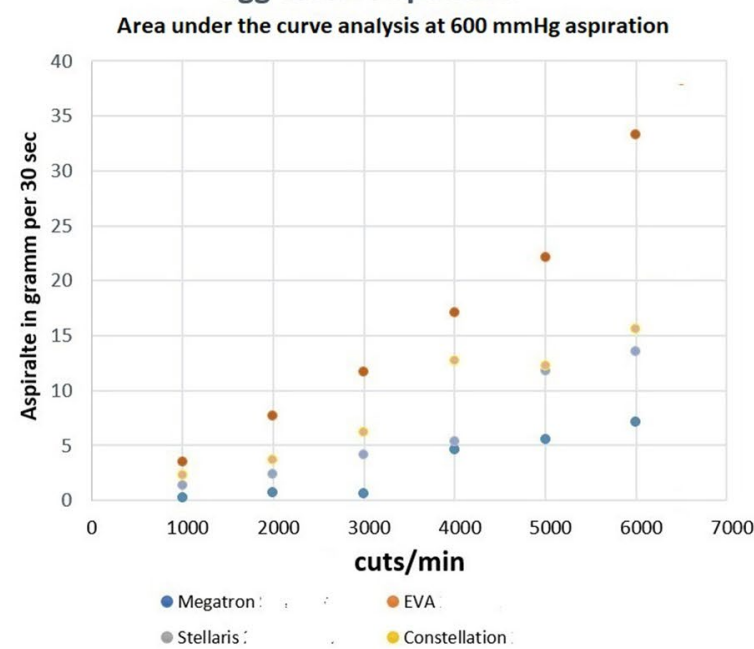

Porcine Vitreous Aspiratin

Area under the curve analysis at $600 \mathrm{mmHg}$ aspıration

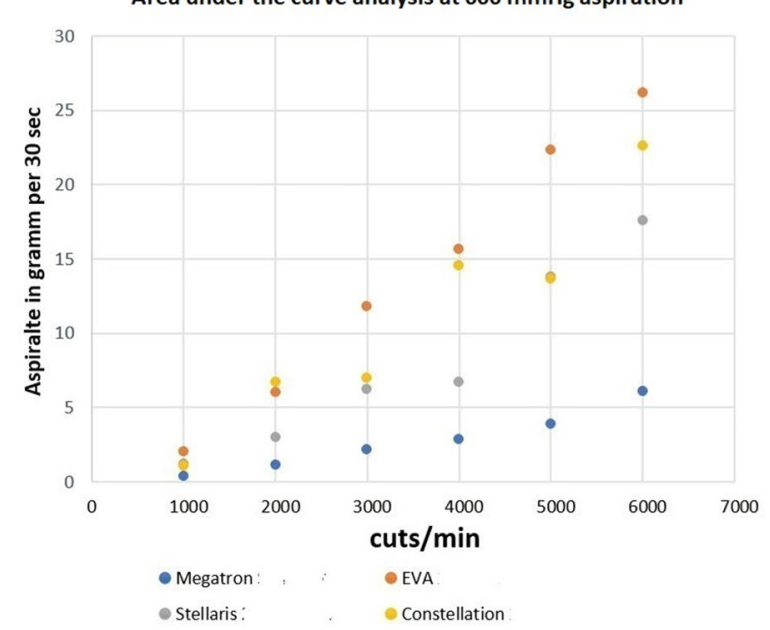

$23 \mathrm{G} \quad$ Water Aspiration

Area under the curve analysis at $600 \mathrm{mmHg}$ aspıration

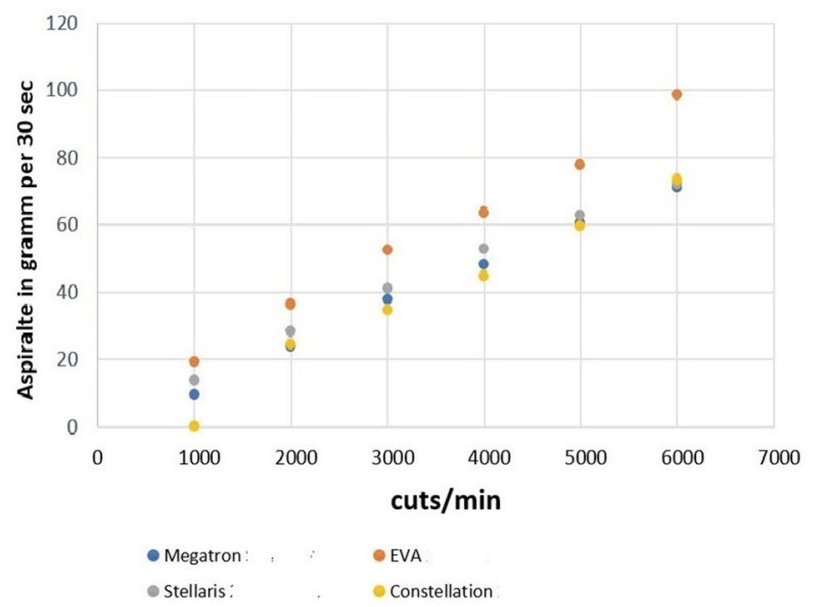

Egg White Aspiration

Area under the curve analysis at $600 \mathrm{mmHg}$ aspıration

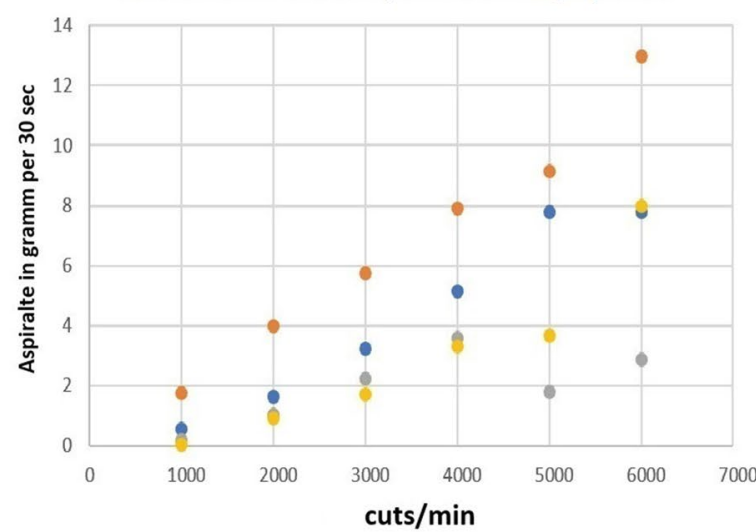

- Megatron: : : EVA

- Stellaris: constellation

Porcine Vitreous Aspiration

Area under the curve analysis at $600 \mathrm{mmHg}$ aspıration

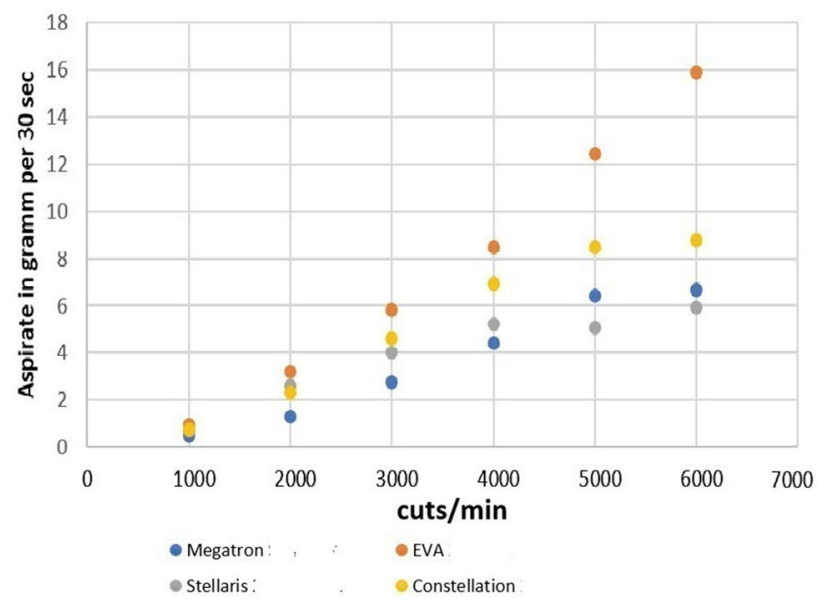




\section{Supplementary Information}

The online version contains supplementary material available at https://doi. org/10.1186/s40942-020-00277-2.

Additional file 1. Blade movement during a duty cycle of the dual-cut Mach2 cutter of the megaTRON S4 ${ }^{\mathrm{HPS}}$ system (Video 1) in comparison to the UltraVit dual pneumatic cutter of the Constellation Visual system (Video 2). Both videos were recorded at $5000 \mathrm{cpm}$ and $200 \mathrm{mmHg}$ aspiration pressure. The dual-cut probe of the megaTRON system showed less vitreous movement at the vitrector opening compared to the UltraVit probe of the Constellation.

Additional file 2. Blade movement during a duty cycle of the dual-cut Mach2 cutter of the megaTRON S4 ${ }^{\text {HPS }}$ system (Video 1) in comparison to the UltraVit dual pneumatic cutter of the Constellation Visual system (Video 2). Both videos were recorded at $5000 \mathrm{cpm}$ and $200 \mathrm{mmHg}$ aspiration pressure. The dual-cut probe of the megaTRON system showed less vitreous movement at the vitrector opening compared to the UltraVit probe of the Constellation.

\section{Acknowledgements}

The authors wish to thank Alcon, Bausch\&Lomb, DORC and Geuder for supplying vitrectomy devices. Furthermore, we are grateful for the funding from the German Federal Ministry of Education and Research (BMBF) (Grant 13GW0051C).

\section{Authors' contributions}

OR substantial contributions to the conception, interpretation of data, substantively revised the work, drafted the work. UD interpretation of data, substantively revised the work. SN substantial contributions to the conception, interpretation of data, substantively revised the work. RD interpretation of data, substantial contributions to the conception, drafted the work and substantively revised it. All authors read and approved the final manuscript.

\section{Funding}

Funded by the German Federal Ministry of Education and Research (BMBF) (Grant 13GW0051C).

\section{Availability of data and materials}

The datasets analyzed during the current study are available from the corresponding author on reasonable request.

\section{Ethics approval and consent to participate}

Eyes were explanted postmortem by a slaughterhouse approved in accordance with the guidelines of the German Regulations for Animal Protection and Slaughter, issued by the German Federal Ministry for Consumer Protection, Food and Agriculture in 2012.

\section{Consent for publication}

Not applicable.

\section{Competing interests}

The authors declare that they have no competing interests.

Received: 31 August 2020 Accepted: 28 December 2020

Published online: 19 January 2021

\section{References}

1. Machemer R, Buettner H, Norton EW, Parel JM. Vitrectomy: a pars plana approach. Trans Am Acad Ophthalmol Otolaryngol. 1971;75(4):813-20.

2. Sharma T, Fong A, Lai TY, Lee V, Das S, Lam D. Surgical treatment for diabetic vitreo-retinal diseases: a review. Clin Exp Ophthalmol. 2016;44(4):340-54.

3. Van Heuven WA. Experiences with partial vitrectomy in patients with proliferative diabetic retinopathy. Mod Probl Ophthalmol. 1972;10:684-9.
4. Peyman GA, Huamonte FU, Rose M. Management of traumatic retinal detachment with pars plana vitrectomy, scleral buckling, and gas injection. Acta Ophthalmol. 1975;53(5):731-7.

5. Peyman GA, Vastine DW, Diamond JG. Vitrectomy and intraocular gentamicin management of Herellea endophthalmitis after incomplete phacoemulsification. Am J Ophthalmol. 1975;80(4):764-5.

6. Peyman GA, Vastine DW, Diamond JG. Vitrectomy in exogenous Candida endophthalmitis. Albrecht Von Graefes Arch Klin Exp Ophthalmol. 1975;197(1):55-9.

7. Hutton WL, Snyder WB, Vaiser A. Surgical removal of nonmagnetic foreign bodies. Am J Ophthalmol. 1975;80(5):838-43.

8. O'Malley C, Heintz RM. Vitrectomy with an alternative instrument system. Ann Ophthalmol. 1975;7(585e8):591-4.

9. Eckardt CM. Transconjunctival sutureless 23-gauge vitrectomy. Retina. 2005;25:208-11.

10. Oshima Y, Wakabayashi T, Sato T, Ohji M, Tano Y. A 27-gauge instrument system for transconjunctival sutureless microinsicion vitrectomy surgery. Ophthalmology. 2010;117:188-93.

11. Teixeira A, Chong LP, Matsuoka N, Arana L, Kerns R, Bhadri P, Humayun M. Vitreoretinal traction created by conventional cutters during vitrectomy. Ophthalmology. 2010;117(7):1387-92.

12. Diniz B, Ribeiro RM, Fernandes RB, Lue JC, Teixeira AG, Maia M, Humayun MS. Fluidics in a dual-pneumatic ultra high-speed vitreous cutter system. Ophthalmological. 2013;229(1):15-20.

13. Magalhaes $O \mathrm{Jr}$, Chong L, DeBoer C, Bhadri P, Kerns R, Barnes A, Fang S, Schor P, Humayun M. Guillotine performance: duty cycle analysis of vitrectomy systems. Retin Cases Brief Rep. 2009;3(1):64-7.

14. Abulon DJ. Vitreous flow rates through dual pneumatic cutters: effects of duty cycle and cut rate. Clin Ophthalmol. 2015:9:253-61.

15. Abulon DJ, Buboltz DC. Performance comparison of high-speed dualpneumatic vitrectomy cutters during simulated vitrectomy with balanced salt solution. TransI Vis Sci Technol. 2015;4(1):6.

16. Magalhães O Jr, Maia M, Maia A, Penha F, Dib E, Farah ME, Schor P. Fluid dynamics in three 25-gauge vitrectomy systems: principles for use in vitreoretinal surgery. Acta Ophthalmol. 2008;86(2):156-9.

17. Rossi T, Querzoli G, Angelini G, Malvasi C, lossa M, Placentino L, Ripandelli G. Fluid dynamics of vitrectomy probes. Retina. 2014;34(3):558-67.

18. Mohamed S, Claes C, Tsang CW. Review of small gauge vitrectomy: progress and innovations. J Ophthalmol. 2017;2017:6285869.

19. Rossi T, Querzoli G, Angelini G, Malvasi C, Rossi A, Morini M, Esposito G, Micera A, di Luca NM, Ripandelli G. Hydraulic resistance of vitreous cutters: the impact of blade design and cut rate. Transl Vis Sci Technol. 2016;5(4):1.

20. Noulas AV, Theocharis AD, Feretis E, Papageorgakopoulou N, Karamanos NK, Theocharis DA. Pig vitreous gel: macromolecular composition with particular reference to hyaluronan-binding proteoglycans. Biochimie. 2002;84(4):295-302.

21. Angi M, Kalirai H, Couplad SE, Damato BE, Semeraro F, Romano MR. Proteomic analyses of the vitreous humour. Mediators Inflamm. 2012;2012:148039.

22. Lee B, Litt M, Bucsbaum G. Rheology of the vitreous body: Part 2. Viscoelasticity of bovine and porcine vitreous. Biorheology. 1994;31(4):327-38.

23. Pavlidis M. Two-dimensional cutting (TDC) vitrectome: in vitro flow assessment and prospective clinical study evaluating core vitrectomy efficiency versus standard vitrectome. J Ophthalmol. 2016;2016:3849316.

24. Lima LH, Deboer C, McCormick M, Kerns R, Bhadri P, Humayun HS. A new dual port cutter system for vitrectomy surgery. Retina. 2010;30(9):1515-9.

25. Chaves de Oliveira PR, Berger AR, Chow DR. Vitreoretinal instruments: vitrectomy cutters, endoillumination and wide-angle viewing systems. Int J Retina Vitreous. 2016:2:28.

\section{Publisher's Note}

Springer Nature remains neutral with regard to jurisdictional claims in published maps and institutional affiliations. 